

\title{
ADVOCATING FOR CHANGE IN NEPAL'S ADULT ENTERTAINMENT SECTOR
}

The United Nations Human Rights Council has a powerful role to play in addressing the worst forms of child labour. Accountability mechanisms such as the Universal Periodic Review (UPR) - which work to support Member States to improve their human rights situation - are therefore widely seen as important opportunities to advocate for change. Ahead of Nepal's third UPR cycle in 2021, the CLARISSA programme met with eight UN Permanent Missions to present recommendations addressing the exploitation of children within Nepal's adult entertainment sector.

\section{BACKGROUND}

Hospitality and entertainment are relatively new and growing sectors in Nepal's capital Kathmandu. The 'adult entertainment sector' (AES) encompasses a diverse range of formal and informal venues, including restaurants, folk dance bars (known as 'dohoris'), erotic dance bars, massage parlours, guest houses, and hotels. It is a sector that has developed in response to an increasing demand for entertainment from a growing urban, and mostly male, population. While not all venues in the AES are exploitative or engage children in sexual services, it is a high-risk environment and within the informal sector in which commercial sexual exploitation of children (CSEC) is known to take place. ${ }^{1}$ At the same time, AES provides employment for women and girls in a context where alternative work opportunities have been limited.

By gathering evidence and collecting stories with children, their families and communities, CLARISSA is working to improve understanding of the factors that drive children to work in Nepal's AES.

"As part of a much wider process of advocacy, beyond the CLARISSA programme, nine recommendations calling for a focus on the informal sector and the worst forms of child labour were subsequently made to the Government of Nepal by the UN Permanent Missions."

\section{CHALLENGES AND OPPORTUNITIES}

Nepal has made steady progress on the protection of child rights since the second UPR cycle (201216), including the landmark introduction of the new Children's Act in 2018, and the new Labour Act, 2017. Nevertheless, the Child Labour (Prohibition and Regulation) Act, 2000 still omits the informal sector leaving those children working in its 'hidden' corners vulnerable to serious rights violations.

The third UPR cycle presented CLARISSA with the opportunity to influence the agenda by providing decision makers with recommendations to the Government of Nepal that are underpinned by the importance of integrating a participatory, adaptive and child-centred approach.

Ahead of the UPR, the CLARISSA advocacy team - led by the Consortium for Street Children in partnership with CWISH and Voice of Children/ChildHope - met with eight Permanent Missions to the UN in Geneva (Croatia, Slovenia, Belgium, France, Switzerland, Poland, Uruguay, Ireland) to share emerging evidence and advocate for recommendations developed by the programme. Research and stories from the Nepal team during these meetings brought the issue to life.

${ }^{1}$ Trafficking and. Exploitation in the Entertainment and Sex Industries in Nepal: A Handbook for Decision-makers, Frederick, Basnyet and Aguettant 2010, Terre des hommes Nepal. 
The CLARISSA note was also emailed to many other Permanent Missions, and some made recommendations based on CLARISSA's emerging evidence (e.g., Italy and the Marshall Islands). As part of a much wider process of advocacy, beyond the CLARISSA programme, nine recommendations calling for a focus on the informal sector and the worst forms of child labour (WFCL) were subsequently made to the Government of Nepal by the UN Permanent Missions.
"The third UPR cycle presented CLARISSA with the opportunity to influence the agenda by providing decision makers with recommendations to the Government of Nepal that are underpinned by the importance of integrating a participatory, adaptive and child-centred approach."

Recommendations directly developed

and advocated for by CLARISSA:

\begin{tabular}{|c|c|c|}
\hline $\begin{array}{l}\text { CLARISSA } \\
\text { RECOMMENDATION }\end{array}$ & $\begin{array}{l}\text { RECOMMENDATION(S) MADE } \\
\text { BY STATE(S) }\end{array}$ & $\begin{array}{l}\text { RECOMMENDING } \\
\text { STATE }\end{array}$ \\
\hline $\begin{array}{l}\text { Ensure that child labour in the informal } \\
\text { sector is incorporated into the Child } \\
\text { Labour (Prohibition and Regulation) Act, } \\
\text { in line with commitments made under the } \\
\text { second UPR cycle. }\end{array}$ & $\begin{array}{l}\text { Ensure that child labour in the informal } \\
\text { sector is incorporated into the Child } \\
\text { Labour (Prohibition and Regulation) Act. }\end{array}$ & Belgium \\
\hline $\begin{array}{l}\text { Take action to mitigate the risk of children } \\
\text { entering the AES sector because of } \\
\text { the Covid- } 19 \text { pandemic, by ensuring } \\
\text { the inclusion of vulnerable children and } \\
\text { families in policy responses. }\end{array}$ & $\begin{array}{l}\text { Ensure inclusion of vulnerable children } \\
\text { and families in policy responses to the } \\
\text { Covid-19 pandemic to minimise the risk of } \\
\text { children getting involved in child labour. }\end{array}$ & Croatia \\
\hline $\begin{array}{l}\text { Develop safe, inclusive and participatory } \\
\text { mechanisms for all children to express } \\
\text { their views and be heard at all levels, } \\
\text { including in developing solutions to } \\
\text { the WFCL. }\end{array}$ & $\begin{array}{l}\text { Develop safe and inclusive mechanisms } \\
\text { for all children to express their views, as } \\
\text { well as finding the solutions for the WFCL. }\end{array}$ & Croatia \\
\hline
\end{tabular}

\section{THE PROCESS}

CLARISSA shared emerging evidence based on two scoping studies, a research report, a rapid review of children in the AES during the pandemic and the Nepal research team's experiences while collecting life stories. Specifically, during the rapid review the team interviewed two child survivors, four employers, two people based at NGOs working in the AES. All indicate a highly complex set of factors at play.

The note focused on:

\section{Omission of the informal sector in national} legislation2: The AES in Nepal is largely informal which is a barrier to preventing children from being recruited and exploited within it. Many venues and businesses are not formally registered, and informal intermediaries, such as female relatives, friends, or neighbours with prior experience of the industry, are often the ones to recruit children. Informal intermediaries can be difficult to detect as they work outside of the legal framework, without a clear identity or fixed premises.

\section{Enforcement of counter-trafficking in the AES ${ }^{3}$ :} There is a need to respond in sustainable and holistic ways that ensure children's protection and rehabilitation. Approaches should be child-centred and include mechanisms that ensure children's voices are listened to, and that children's protection and rehabilitation

\section{The impact of Covid-19 on the AES ${ }^{4}$ :}

Covid-19 has exacerbated social inequalities in Nepal. Two key consequences have been a lack of financial protection for children employed in this sector and an increase in the numbers of children working in the AES, as a result of the poverty and inflation caused by the pandemic. 


\section{ENGAGING WITH THE UPR PROCESS DURING THE PANDEMIC}

With face-to-face meetings suspended, virtual meetings enabled CLARISSA colleagues in Nepal to meet directly with diplomats based in Geneva and share their experiences. This interaction was warmly welcomed by diplomats and helped to bring the issues to life. Similarly, statements during the Adoption meeting are usually delivered in person in Geneva so CLARISSA's Advocacy Expert in Nepal was easily able to pre-record a video message to share directly with the Human Rights Council.

To develop this statement, CLARISSA colleagues from the Consortium for Street Children and Nepal worked closely together to reiterate the need to focus on the worst forms of child labour in the adult entertainment sector and highlighted the importance of a child-centred approach in generating solutions to child labour.

\section{LOOKING FORWARD}

The inclusion of these recommendations will enable the Government of Nepal to be held accountable for their progress.

Other relevant recommendations included:

- Strengthening the implementation and enforcement of existing child labour legislation (Italy and the Marshall Islands).

- Adopting additional measures to strengthen the National Plan of Action for Eradicating Child Labour by 2028 (Italy).

- Paying special attention to eradicating all forms of child labour and preventing child labour in the informal sector (Russian Federation).

Since the start of the third UPR cycle, CLARISSA has continued to engage directly with the Government of Nepal and offer its support in addressing the drivers of the WFCL.

After several months reviewing the 233 recommendations received, the Government of Nepal returned to the Human Rights Council's 47th session in July 2021 to inform the Council which recommendations it will support, and which it will acknowledge. This is known as an 'Adoption' meeting. Supported recommendations are those which a government pledges to implement; in this cycle, the Government of Nepal supported 196 out of 233 recommendations.

During this meeting, Kushum Sharma, Advocacy Expert, CLARISSA Nepal, addressed the Human Rights Council. All the recommendations developed by the programme, and made to Nepal, have been supported by the government.

CLARISSA delivered a statement during the Adoption meeting, welcoming the Government of Nepal's public commitment to including child labour in the informal sector in national legislation and developing participatory mechanisms for children in the WFCL to express their views and be heard. This is the first step in mitigating the risk of children entering the AES because of the pandemic.

We called on the government to act swiftly to implement these recommendations and pledged the programme's support and expertise in this process. As Nepal moves into the implementation phase, CLARISSA will offer ongoing support and will monitor the implementation of these recommendations.

It is hoped that by influencing the UPR recommendations, CLARISSA will be in a stronger position to affect long-term and sustainable change as the programme unfolds.

\section{FURTHER READING}

Yunus, R.M. (2020) Addressing Informal Labour Intermediaries in the Context of Child Labour: Evidence Review Across Nepal, Bangladesh, and Myanmar, CLARISSA Emerging Evidence Report 3,

Brighton: Institute of Development Studies

Oosterhoff, P. and Hacker, E. (2020) Social Norms, Labour Intermediaries, and Trajectories of Minors in Kathmandu's Adult Entertainment Industry, CLARISSA Working Paper 1, Brighton: Institute of Development Studies

\section{CREDITS}

This Spotlight Story was written by Clare Gorman (Alburnum Associates) with input from Kushum Sharma, Sudhir Malla (Voice of Children) and Lucy Halton (Consortium for Street Children) and edited by Vivienne Benson, CLARISSA Communications Lead.

DOI:10.19088/CLARISSA.2021.010

"Approaches should be child-centred and include mechanisms that ensure children's voices are listened to, and that their needs and desires are taken into account."



Kushum Sharma, Advocacy Expert, CLARISSA Nepal, delivers video statement to the Human Rights Council in the Adoption meeting. 


\section{EMERGING EVIDENCE}

CLARISSA works by co-developing with stakeholders practical options for children to avoid engagement in the WFCL in Bangladesh and Nepal. The programme's outputs are co-designed and collaboratively produced to enhance local ownership of the knowledge, and to ensure that the emerging evidence is rooted in the direct experience of the people most affected on the ground. The participatory processes which underpin the programme are designed to generate innovation from the ground which can sustainably improve the lives of children and their families.

\section{MAPPING OF CHILDREN ENGAGED IN THE WORST FORMS OF CHILD LABOUR IN THE SUPPLY CHAIN OF THE LEATHER INDUSTRY IN BANGLADESH}

This mapping provides a detailed assessment of where children are working in the leather supply chain in Bangladesh. It evidences the children's perceptions of themselves and others as child labourers - the jobs and areas of the sector that they feel comprise WFCL, and the jobs they feel are the most difficult or dangerous to do and that children should not have to do.

Download: https://clarissa.global/resource/mapping-ofchildren-engaged-in-the-worst-forms-of-child-labour-in-thesupply-chain-of-the-leather-industry-in-bangladesh/

\section{DESIGNING A \\ PARTICIPATORY \\ programme AT SCALE}

This paper shares the design and overarching methodology of CLARISSA, which was codeveloped with all consortium partners during and since the co-generation phase of the programme (September 2018-June 2020). This is also a useful reference point for other programmes trying to build large-scale participatory processes. It provides a clear overview of the CLARISSA approach, the design, and how it is being operationalised in context.

Download: https://clarissa.global/resource/designing-aparticipatory-programme-at-scale/

\section{BONDED: LIFE STORIES FROM AGRICULTURAL COMMUNITIES IN SOUTH-EASTERN NEPAL}

This paper is an external qualitative analysis of over 150 life stories from individuals living in an area with high levels of bonded labour. These stories were previously analysed during a workshop through a collective participatory analysis. The participatory analysis gives historical insights on pathways into child labour, but although some of the social norms persist this situation has changed.

Download: https://clarissa.global/resource/bonded-lifestories-from-agricultural-communities-in-south-easternnepall

\section{EXPOSING THE WORST FORMS OF CHILD LABOUR IN BANGLADESH'S LEATHER SECTOR}

A dramatic decrease in the global demand for leather since Covid-19 has led to the collapse of the supply chain with workers, especially children, bearing the worst of the brunt. As cracks in the industry's surface widen, new research from CLARISSA shines a light into its hidden corners, revealing examples of the WFCL at almost every turn.

Download: https://clarissa.global/resource/exposing-theworst-forms-of-child-labour-in-bangladeshs-leather-sectorl

Find out more:

- Access all the latest publications: https://clarissa.global/the-publications/

- Find out about the approach: https://clarissa.global/the-approach/

- Have a listen to the conversation series: https://soundcloud.com/user-91932878

The Child Labour: Action-Research-

Innovation in South and South-Eastern Asia (CLARISSA) is a consortium of organisations committed to building a participatory evidence base and generating innovative solutions to the worst forms of child labour in Bangladesh and Nepal.

\.arissa@ids.ac.uk

https://clarissa.global

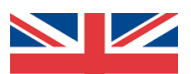

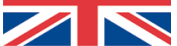
UKaild from the British people



(C) Institute of Development Studies 2021. This terms of the Creative Commons Attribution
International licence (CC BY), which permits unrestricted use,
distribution, and reproduction in any medium, provided the origina distribution, and reproduction in any medium, provided the
authors and source are credited and any modifications or adaptations are indicated. is an Open Access report distributed under the terms of the Creative Commons Attribution 4.0

This report has been funded with UK aid from the UK government (Foreign, Commonwealth \& Development Office -FCDO, formerly DFID). The opinions expressed are those of the authors and do not necessarily reflect the views or policies of IDS or the UK government.

\begin{abstract}
y@ChildLabourActn
\end{abstract}

